\title{
In-situ Observation of Short Fatigue Crack Propagation in Oxygenated Water at Elevated Temperature and Pressure
}

\author{
J. Duff and T.J. Marrow ${ }^{\dagger}$ \\ Materials Performance Centre, Department of Materials, University of Manchester, \\ M1 9PL, Manchester
}

James.marrow@materials.ox.ac.uk (corresponding author) (tel: 01865 273939, fax: 01865 273789)

\begin{abstract}
A new method is demonstrated for in-situ measurement of short crack propagation rates during a corrosion fatigue test of an austenitic stainless steel within a windowed autoclave at $250^{\circ} \mathrm{C}, 50$ atmospheres, oxygenated water. Digital image correlation is used to monitor crack growth through measurement of the opening displacements of defects; either focused ion beam (FIB) milled notches from which fatigue cracks initiated, or stress corrosion cracks that subsequently propagated by fatigue.
\end{abstract}

\section{Keywords}

Stainless steel (A), corrosion fatigue (C), reactor conditions (C)

\section{Introduction}

In the austenitic stainless steel components of the cooling circuits in light water nuclear reactors, fatigue damage may develop through high-cycle fatigue: from flowinduced vibration or thermal loading from turbulent mixing, or low-cycle thermal fatigue that is driven from thermal stratification. There exist considerable data for the complex interactions between water chemistry, temperature, loading rates and

\footnotetext{
*NOTICE: this is the author's version of a work that was accepted for publication. Changes resulting from the publishing process, such as peer review, editing, corrections, structural formatting, and other quality control mechanisms may not be reflected in this document. Changes may have been made to this work since it was submitted for publication. A definitive version was subsequently published in Corrosion Science (2013), http://dx.doi.org/10.1016/j.corsci.2012.10.030

${ }^{\dagger}$ Permanent address: Department of Materials, Oxford University, UK. The work was conducted while TJM was Director of the Materials Performance Centre.
} 
material chemistry and structure, which are used in both design and operation to avoid fatigue-induced failure [1]. These data are obtained either through post-test destructive characterisation of smooth specimens, or from studies of pre-cracked test specimens, employing electrical methods to measure crack propagation rates (e.g. [2]). In the absence of a pre-existing defect, the physically short fatigue crack regime may dominate the fatigue lifetime; short cracks have size typically of the order of the microstructure length scale. The chemistry of the crack tip environment is not necessarily that of the bulk environment [3], and may depend on crack size [4]. There is merit, therefore, in direct studies of the propagation rates of short corrosion-fatigue cracks, for comparison with the behaviour of longer cracks, to ensure that the design dataset is conservative.

However, the experimental investigation of short corrosion-fatigue crack growth behaviour is particularly challenging, especially in light water reactor environments. The detection of crack initiation is feasible by electrochemical noise methods, and has been demonstrated in both ambient and elevated temperature aqueous environments (e.g. [5], [6]). But, whilst observations of the nucleation and growth of fatigue cracks can be achieved quite readily in dry ambient temperature environments by optical observation or replica methods (i.e. higher resolution studies of acetate replicas which periodically record the specimen surface) [7], and such methods are also applicable in wet ambient temperature environments (for instance, Akid et al used replica methods to study short fatigue crack growth rates in low alloy structural steel in a saline environment [8]); there are no techniques reported that are suitable for studies of short corrosion fatigue crack growth rates in high temperature, high pressure water.

For environmentally-assisted cracking, it may be very important for the sample to remain in the active environment throughout the cracking process; interruption of testing for examination, with associated changes in environment and mechanical loading, may interfere with the mechanism of corrosion fatigue. It is highly desirable to be able to see into the sealed autoclave chamber that is required for high temperature and pressure testing, and make in-situ observations of crack development. A windowed "imaging" autoclave has therefore been developed [9] to enable the optical observation of high temperature aqueous corrosion and cracking processes.

Optical observations have limited resolution, particularly in aqueous environments, and short fatigue cracks may be difficult to observe directly. Recent work has demonstrated the advantages of applying Digital Image Correlation (DIC) [10] to optical observations; cracks can be identified and their development quantified, prior to them being visible using conventional techniques. DIC is a technique that enables the sensitive measurement of local surface displacements between successive images. It allows full field strain data to be obtained throughout the deformation of a material [10]. It has been applied to study crack behaviour in a broad range of materials (e.g. [11-13]). In stress corrosion studies, DIC has proved very useful for the investigation of crack initiation and propagation in austenitic stainless steel in a range of environments, including atmospheric corrosion [14], aqueous solutions [15, 16] and high-temperature, pressurised water [9].

DIC is achieved, in brief, via the discretisation of an image into multiple interrogation windows or patches whose contents may be correlated with the same features in 
images subsequently acquired. Displacement vectors are obtained for the change in position of each interrogation window; strain distributions across the full image may then be calculated from the gradients of the displacement field. Surface crack openings cause measureable displacement steps and so can be visualised as a map of localized strains. As displacement vectors are calculated in pixel dimensions, this technique is independent of scale, with the quality of results depending on the digital image, in particular its bit depth, resolution and the consistency of the captured images. In theory (and usually in practice), the technique allows displacement measurement with sub-pixel resolution; suitable samples display a random, homogenous speckle pattern [10]. Displacement vector accuracy is dependent on the interrogation window size employed and while larger windows provide more accurate measurements, they decrease the spatial resolution of the resulting map of displacements or strains.

Digital image correlation, coupled with the windowed autoclave [9], provides the potential for providing new and unique information on degradation processes. This paper describes the demonstration of this methodology, reporting the first direct measurements of short fatigue crack propagation rates in a high temperature and highpressure aqueous environment.

\section{The Imaging Autoclave}

The windowed "Imaging Autoclave" was designed and built by Cormet Testing Systems (Helsinki, Finland) to a specification by The University of Manchester, and has previously been used, with digital image correlation, to study Stress Corrosion Cracking (SCC) in high temperature oxygenated water [9]. It is a modified slow strain rate testing autoclave with a sapphire viewing-window in the base. Conditioned water is supplied from a recirculating loop by means of a high-pressure pump. Figure 1(a) shows a cross-section of the autoclave and the jig for specimen loading; the autoclave itself is shown in Figure 1(b). The autoclave body is manufactured from AISI 316L stainless steel, with a volume of 0.9 litres. The design operating pressure is $50 \mathrm{bar}$, with a design operating temperature of $250^{\circ} \mathrm{C}$.

The loading jig forms part of the autoclave base, and is designed to test uniaxial fourpoint bend specimens or bi-axial (cruciform) bend specimens. The load is applied via the push rod (2), which is sealed by the push rod slide bearing (1) to allow free movement of the rod without steam leakage. The load is controlled via a load cell with a nominal rating of $10 \mathrm{kN}$ (Interface $1210 \mathrm{AF}-2 \mathrm{~K}-\mathrm{B}$, standard error of $0.04 \%$ ). The main autoclave seal, (3) has outer diameter (OD) of $110 \mathrm{~mm}$. A polished sapphire window (4) is incorporated in the autoclave base. It has a $40 \mathrm{~mm}$ diameter and $8 \mathrm{~mm}$ thickness. The sample surface is $4 \mathrm{~mm}$ from the inner surface of the sapphire window.

A recirculating loop conditions the water that enters the autoclave. The low-pressure side has a maximum operating pressure and temperature of 3 bar and $40^{\circ} \mathrm{C}$ respectively, while the high-pressure side has a design pressure and temperature of 50 bar and $250^{\circ} \mathrm{C}$. The heating within the autoclave was controlled by a West 6100 Controller Unit, with temperature monitored by K-Type Thermocouples at two points separated by approximately $100 \mathrm{~mm}$; the water inlet to the autoclave and a probe within the autoclave located within $15 \mathrm{~mm}$ of the sample. The reduced insulation of 
the sapphire window introduces a temperature difference across the autoclave chamber of $10^{\circ} \mathrm{C}$ between these. The measurement error of the thermocouples is less than $1{ }^{\circ} \mathrm{C}$. The reported temperature is that close to the sample. Water is pumped from a 135-litre storage tank at a flow rate of up to $5 \mathrm{l} / \mathrm{hr}$ by means of a high-pressure pump (Prominent HP2). A second pump (Johnson MDR45P2) circulates water from the storage tank through water-chemistry analysers to allow monitoring and control. Pressure was monitored by a Bourdon Haenni Type E913 pressure transducer rated to 60 bar with a standard error of $0.3 \%$, and was recorded using a West 2300 controller unit. The analysers include a dissolved oxygen sensor, a dissolved hydrogen sensor (both Orbisphere 510 with a range of 0 to 1000 p.p.b.) and a conductivity sensor (ABB, AC221 with a range 0 to $10 \mu \mathrm{S} / \mathrm{cm}$ ). The system can run under deoxygenated conditions, oxygenated conditions (1000 p.p.b. $\max$ ) or under hydrogenated conditions, controlled using the partial pressure of hydrogen within the storage tank. For oxygenated or deoxygenated input water, the flow from the circulation pump is configured such that water is taken from the storage tank and analysed directly. Automatic adjustment to control the oxygen content of the water in the storage tank is made by computer controlled magnetic valves from $\mathrm{N}_{2}$ or $\mathrm{N}_{2} / 2 \% \mathrm{O}_{2}$ gas supplies. The flow loop can be reconfigured to allow analysis of the return water. Water purification is carried out by two ion exchange columns (Veolia Water Solutions and Technologies), which maintain feed-water conductivity by removing dissolved species directly from the storage tank water and also water returning from the autoclave. A chemical mixing tank and circulation pump may be used for chemical doping of the storage tank water.

Renishaw Ltd designed the optical system, to the specification of the University of Manchester. It utilises an InVia Raman spectroscope with a Raman probe, allowing the transmission of the $514 \mathrm{~nm}$ laser source to the specimen by means of a fibre-optic cable. It incorporates a video camera for focusing the Raman probe and a high specification camera (ImagePro X CCD, 14 bit, up to 14 frames/second, $2048 \times 2048$ pixels) to collect images for DIC, with a switching mirror to change the mode of operation. The microscope objective lens (Olympus x20 "super long" working distance lens) has a working distance of $21 \mathrm{~mm}$ in air, increasing to $32.5 \mathrm{~mm}$ when the refractive index of the window and water are included. The lens is brought close to the sapphire window via an optical extension tube to reduce the thermal load on the other components. The sample is illuminated using a $100 \mathrm{~W}$ white light incandescent bulb, with the light passing through the window before entering the probe optics. Position control of the optical system by the XY stage (ProScan11, manufactured by Prior) allows surface mapping over a range of $\pm 4 \mathrm{~mm}$ from the centre of the sapphire window. Digital image correlation was performed using a networked Dual Processor PC $(2 \times 2.8 \mathrm{GHz}$ Processors, $2 \mathrm{~Gb}$ RAM), with Davis Strain Master 2D software (version 7.2) for acquisition and visualisation, (LA Vision, Germany). With the $\mathrm{x} 20$ objective lens the field of view through the sapphire window is approximately 450 $\mu \mathrm{m} \times 450 \mu \mathrm{m}$, with an image pixel size of $0.23 \mu \mathrm{m}$. 


\section{Experimental Details}

\section{Sample Preparation}

The material tested was 304L stainless steel plate (Cr:18.15, Ni:8.60, C:0.055, Mn:1.38, P:0.032, S:0.005, Si:0.45, N:0.038, Fe:Bal, wt\%) with an initial thickness of $13 \mathrm{~mm}$. The microstructure of this material is reported in detail in [17]. Equal amounts were milled from both sides to produce rectangular bars that were $90 \mathrm{~mm}$ in length and $10 \mathrm{~mm}$ in width with a final thickness of $7 \mathrm{~mm}$. The observed surface was electro-polished and electro-etched to produce a suitably speckled finish for DIC. The electro-polishing solution was a $92 \%$ acetic acid, $8 \%$ perchloric acid mix; a voltage of $42 \mathrm{~V}$ for one minute was applied. The same solution was used for electroetching, with an applied voltage of $13 \mathrm{~V}$ for 20 seconds.

Previous fatigue tests, using rotating-bend (zero-mean stress) specimens, had shown that fatigue crack nuclei in austenitic stainless steels developed only at stress amplitudes that were close to the fatigue limit [18-19], which has a magnitude close to the proof stress. Fatigue initiation at such amplitudes under tension-tension loading is therefore difficult in austenitic stainless steels without gross yielding of the specimen; such deformation could not be accommodated in the autoclave's loading jig. The objective of this work was to demonstrate the feasibility of studying short fatigue crack propagation within an autoclave; fatigue crack initiation was therefore achieved by introducing short crack nuclei via alternative methods.

For the first fatigue test in ambient temperature and pressure water, crack initiating features were introduced by Focused Ion Beam (FIB) milling of sharp notches; a technique that had been previously been applied to initiate short fatigue cracks in a Magnesium alloy [20]. Notches were milled in the test specimen using an FEI Nanolab Nova Dual Beam FIB with a gallium ion source at a beam current of $2 \mu \mathrm{A}$, which had been calibrated to achieve a milling rate of $60 \mu \mathrm{m}^{3}$ per minute in stainless steel. Four notches were milled; three were $30 \mu \mathrm{m}$ long x $4 \mu \mathrm{m}$ wide, and one $50 \mu \mathrm{m}$ $\mathrm{x} 4 \mu \mathrm{m}$. Based on the milling rate and the milling time, their expected depth was approximately $20 \mu \mathrm{m}$. There was a separation of $80 \mu \mathrm{m}$ between each notch (Figure 2).

For the second fatigue test at elevated temperature and pressure, instead of FIB notches as fatigue crack initiation sites, intergranular stress corrosion cracks that had initiated during a static-load test were used. The surface preparation of the sample, applied prior to the stress corrosion test, was the same as for the FIB-notched sample. The intergranular stress corrosion cracks were obtained by stressing the sample above yield $(200 \mathrm{MPa})$ in 1000 p.p.b. oxygenated water (100 $\mu \mathrm{S}$ feed-water conductivity) at $250^{\circ} \mathrm{C}$ for 30 days. Cracks were identified by loading/unloading of the sample at the end of this period, with digital image correlation applied to detect their opening strains. An example of the optical observation at the location of one crack (HT-Crack 1) is shown in Figure 3, together with DIC strain map data from the stress corrosion test to aid its visualisation; the reported strains are nominal, the total surface length is approximately $80 \mu \mathrm{m}$. 


\section{Ambient Temperature Fatigue}

The ambient temperature test was run using the autoclave at a water temperature of $20^{\circ} \mathrm{C}$, an oxygen content of 1000 p.p.b. dissolved oxygen and atmospheric pressure (100 $\mu \mathrm{S}$ feed-water conductivity). The slow strain rate system for the imaging autoclave can be run under either load control or displacement control. Displacement control was used for cyclic loading in this work. The maximum possible speed of the pull $\operatorname{rod}$ is $19 \mu \mathrm{m} / \mathrm{s}$ and this value was initially used. For a pull rod displacement amplitude of $100 \mu \mathrm{m}$ with a triangular waveform the cyclic frequency was $0.045 \mathrm{~Hz}$ (approximately 3 cycles per minute), causing the load to cycle between $700 \mathrm{~N}$ and $2000 \mathrm{~N}$. The corresponding surface stress amplitude was $170 \mathrm{MPa}$, with a maximum stress of $270 \mathrm{MPa}$. After 25,000 cycles under these conditions, the pull rod speed was reduced to $2.5 \mu \mathrm{m} / \mathrm{s}$, with a corresponding cycle frequency of $0.007 \mathrm{~Hz}$ (one cycle in 2.4 minutes). The load cycle increased to between $750 \mathrm{~N}$ and $2200 \mathrm{~N}$, with stress amplitude of $200 \mathrm{MPa}$ and maximum stress of $295 \mathrm{MPa}$. A total of 33,500 cycles were performed before the test was suspended, with the total time under fatigue being approximately 14 days or 336 hours.

Optical observations were made, through the sapphire window, at intervals during the fatigue test. Thirty images, at intervals of 1 second, were collected at each observation and were then averaged to correct for any vibrational effects. The exposure time for an individual image was $2500 \mu \mathrm{s}$. Fatigue cycling was suspended for the observations, which were made with the sample at the maximum load (295 $\mathrm{MPa})$ and almost unloaded $(7 \mathrm{MPa})$. The observations were made at nine locations, in a $3 \times 3$ grid, with a $25 \%$ overlap between adjacent images to allow for the image stitching. Each FIB notch was at the centre of at least one image, and digital image correlation was applied to the individual images, not the stitched image montage; artefact errors of pixel magnitude would be obtained at the image joints otherwise. An example image, averaged for vibration correction, is shown in Figure 4(a). The contrast is relatively low due to the combined effects of the sapphire window and water; image pre-processing was applied to correct for localised brightness variations and to enhance the contrast. A montage, stitched from the $3 \times 3$ array of processed images, is shown in Figure 4(b) to illustrate the total area of observation (approximately $0.75 \mathrm{~mm} \times 0.75 \mathrm{~mm}$ ) and the quality of the final images. After the fatigue test, the sample was observed using a scanning electron microscope (Philips XL-30 FEG-SEM). It was first rinsed with alcohol and dried with compressed air. SEM observations of the notches are shown in Figure 5; none show evidence of fatigue crack propagation.

\section{Elevated Temperature Fatigue}

The elevated temperature fatigue test was carried out at a water temperature of $250^{\circ} \mathrm{C}$, an oxygen content of 1000 p.p.b. dissolved oxygen and 50 atmospheres pressure (100 $\mu \mathrm{S}$ feed-water conductivity). The fatigue loading was imposed by displacement control; a pull rod speed of $2.5 \mu \mathrm{m} / \mathrm{s}$ was used with a corresponding cycle frequency of $0.007 \mathrm{~Hz}$ with a triangular waveform. The load cycled between $750 \mathrm{~N}$ and $2200 \mathrm{~N}$, giving a stress amplitude of $200 \mathrm{MPa}$ and maximum stress of $295 \mathrm{MPa}$. A total of 30,802 cycles were performed before the test was suspended, with the total time under fatigue loading being approximately 51 days (1224 hours). As before, the cracks were observed through the sapphire window at intervals during the test and images 
were recorded at the maximum stress of $295 \mathrm{MPa}$ and minimum stress of $7 \mathrm{MPa}$. Optical observation by conventional optical microscopy at the end of the test (Figure 3) showed no discernible change in the appearance of the cracks.

\section{Digital Image Correlation Analysis}

In DIC analysis, the initial image is divided into multiple smaller interrogation windows; a displacement vector is calculated for each window by correlation of features, and the resulting vectors are combined to give an overall displacement map; the precision of the displacement vectors increases significantly with increasing window size. In previous studies of intergranular stress corrosion cracking in the windowed imaging autoclave [9], relatively small interrogation windows $(32 \times 32$ pixels) were used. This was necessary since the locations of crack initiation were unknown; a high spatial resolution was required in order to map the cracks and their propagation through the microstructure. The spatial resolution (i.e. the grid spacing of displacement vectors) achieved was $5.5 \mu \mathrm{m}$, and the confidence in displacement vector magnitude was approximately $0.07 \mu \mathrm{m}$ (one standard deviation).

In this experiment, the locations of the notches and cracks are known. As a consequence, suitable placement of large image correlation windows allows more precise measurements to be obtained of the relative displacements across the notches and cracks. A crack or notch will open elastically when a stress is applied, and crack propagation will increase the effective elastic compliance of a notch or crack, such that the change in notch opening displacement with applied load will increase as the crack propagates in depth. The high sensitivity of DIC analysis to surface displacements may be used to observe changes in notch or crack compliance, and hence detect the effects of crack propagation.

\section{Ambient Temperature Fatigue}

The obvious analysis is to measure the compliance of the notches, and to detect the change in compliance through the fatigue test; the compliance may be estimated from the change in notch opening between minimum and maximum load. A displacement map is presented, in Figure 6a, of the relative displacements in the direction of the applied stress (i.e. perpendicular to the notches); these were obtained by correlating images recorded, in the first cycle (" 0 cycles"), at the minimum and maximum stresses. The displacement map obtained similarly in the last cycle ("33,500 cycles") is shown in Figure 6b. The DIC analyses used $64 \times 64$ pixel windows with a $25 \%$ overlap. The total displacement, approximately 8 pixels $(\sim 2 \mu \mathrm{m})$, is due both to elastic straining of the sample and also its displacements relative to the lens; out-ofplane movements affect the image focus and introduce artificial changes in the DIC measured displacement. It is therefore not possible to reliably measure the effect of fatigue loading on the notch opening compliance using such measurements.

However, correlating images recorded at the same load detects the effect of fatigue loading more clearly; this removes the artefacts from out-of-plane movements of the sample relative to the lens, since the sample position is remains constant at the same load. Figure $6 \mathrm{c}$ shows a displacement map for the image recorded at peak stress $(\sim 295 \mathrm{MPa})$ at 0 cycles correlated with the image recorded at peak stress at 33,500 
cycles. The displacements obtained by similarly correlating images recorded when the sample was unloaded $(\sim 7 \mathrm{MPa})$ are shown in Figure $6 \mathrm{~d}$. As before, the DIC analysis used $64 \times 64$ pixel windows with a $25 \%$ overlap. The uncertainty in the displacement magnitudes for images correlated at the same stress (Figure $6 \mathrm{c}$ and Figure 6d), estimated as the displacement magnitude standard deviation measured for a rigid body in-plane movement under equivalent imaging conditions, is 0.08 pixels or $\sim 0.02 \mu \mathrm{m}$.

Figure $6 \mathrm{c}$ shows that there is a displacement change across notches 2 to 4 at the peak stress after 33,500 cycles; there is no clear change for notch 1 . This can be due to a change in depth of the notch, consistent with equation (1), or plastic deformation from to the stress concentrating effect of the notch. However, when the sample is unloaded, any displacements relative to the initial state could only be due to plastic deformation. The displacement map at the minimum stress (Figure 6d) indicates that any such deformation is negligible; hence only crack propagation may have occurred.

To measure the displacements more accurately, a window size of 128 x 128 pixels was used to correlate images at maximum or minimum stress, relative to a reference image at the same stress at 0 cycles. The window overlap was $87 \%$ to increase the number of displacement vectors; this reduces measurement noise when the displacement field is smooth, as it is here between the notches. A data 'mask' was applied so that displacement vectors were only selected within blocks on either side of notches. Each block was of the order of $300 \times 200$ pixels $(\sim 70 \mu \mathrm{m} \times 45 \mu \mathrm{m})$, and was obtained using windows that did not overlap any notch (centre to centre distance of approximately 400 pixels $(\sim 100 \mu \mathrm{m})$. An elastic finite element analysis of the displacement fields associated with surface cracks under flexural loading [12] has shown that the measurement of opening displacements by this method is insensitive to the position of the analysed blocks. The magnitudes of the displacement vector component in the direction of the applied stress in each block were averaged, and the difference between adjacent blocks gave the change in notch opening, relative to the reference at 0 cycles. The standard deviation of the displacements in each block was measured to be 0.02 pixels; this is the expected variance at this window size for optimal images [21]. The uncertainty in the relative opening displacement across the notch was therefore conservatively estimated at 0.04 pixels, or $0.01 \mu \mathrm{m}$.

This analysis obtained the change in notch opening displacement as a function of the number of fatigue cycles applied; the data at maximum stress ( $295 \mathrm{MPa})$ for each of the four notches are presented in Figure 8. The residual notch opening displacement in the unloaded state $(\sim 7 \mathrm{MPa})$ remained less than $0.01 \mu \mathrm{m}$ and did not measurably change for all four notches. At the maximum stress, the notch opening displacement increases as the number of fatigue cycles increases for notches 2 to 4 . The increase is significant compared to the measurement uncertainty, though there is no measurable change for notch 1 .

\section{Elevated Temperature Fatigue}

Images of HT-crack 1 within the imaging autoclave at maximum load during the fatigue test are shown in Figure 7, with superposed maps of the maximum normal strain, obtained by DIC with respect to the reference image at the same stress, recorded at the start of the fatigue cycling. These maps are useful to visualise the 
crack and show there is a progressive increase in crack opening, indicated by the nominal strain magnitude. There is no discernible change in length; the shorter length of the strain feature visualised at 6983 cycles is attributed to changes in crack opening towards the ends of the original crack that are below the detection threshold. The final crack has the same length as that observed prior to the corrosion fatigue test (Figure 4c), but has developed a greater opening. A second crack, HT-crack 2, did not develop any change in opening or length that was visible in its strain map.

To obtain the crack opening displacements more accurately, the relative displacements between two blocks either side of the crack were used as before; here the blocks had size approximately $250 \times 250$ pixels with a centre-to-centre distance of approximately 500 pixels, for data obtained at $128 \times 128$ pixels with $87 \%$ overlap. Testing at elevated temperature had no measurable effect on the image quality, and the uncertainty in the relative displacement measured in that manner was $0.01 \mu \mathrm{m}$, as previously. Data for the change in crack opening displacement with the number of cycles are shown in Figure 8, compared with the FIB notches at room temperature. There is a significant and progressive increase in the opening displacement of HTcrack 1. The data for HT-crack 2 are more ambiguous; there is an apparent increase, but it is of the order of the measurement uncertainty.

\section{Post-Fatigue Test Characterisation of a FIB-notch}

The observed change in crack opening displacement indicates that the compliance of the notches and cracks has increased with fatigue cycling; the lack of residual opening after unloading implies that this is due to fatigue crack growth, but there was no evidence of crack propagation at the observed surface. In-situ observations of fatigue crack nucleation from FIB-milled notches in a Magnesium alloy, obtained using three-dimensional synchrotron computed tomography [20], showed the crack propagated from the tip of the sharp notch before crack propagation could be observed at the free surface as the rectangular shape of the notch at the surface provided a much less significant stress concentrator; with continued fatigue cycling a semi-elliptical crack was eventually developed. Sectioning of Notch 4 was therefore carried out, using FIB-milling, to investigate for crack propagation from the notch tip.

A deposit of platinum was laid over the notch to prevent milling damage; this filled the notch with platinum. The notch was cross-sectioned from one end towards its centre, using an access trench orthogonal to the surface. Tilting the sample by $45^{\circ}$ allowed the notch cross-section to be viewed. Initially there was no clear evidence of a crack, but subsequent straining in tension caused a crack to become visible at the tip of the notch (Figure 9). The crack is concluded to have propagated during the fatigue test; austenitic stainless steel is a ductile alloy, and brittle fracture from a shallow stress concentration is unreasonable (the platinum within the notch has also strained plastically). Accounting for $45^{\circ}$ tilt of the imaged surface, the notch depth is measured to be $26 \mu \mathrm{m}$, with the crack extending $16 \mu \mathrm{m}$ from the notch tip. 


\section{Discussion}

A crack, or notch, will open elastically when a stress is applied; the opening depends on the geometry of the crack and the nature of the applied load. For a semi-elliptical crack, the surface opening displacement, $\delta$, at its centre [22] is:

$$
\delta=\frac{4\left(1-v^{2}\right)}{E \cdot E(k)} \sigma_{T} a\left\{1+\frac{\sigma_{B}}{\sigma_{T}}\left[1+\frac{2 a}{t} D(k)\right]\right\} S
$$

where $\sigma_{B}$ and $\sigma_{T}$ are the bending and tensile stresses, $E$ is the elastic modulus, $v$ is Poisson's ratio, $a$ is the crack depth and $S$ is the boundary correction factor (from [23]); functions $E(k)$ and $D(k)$ are:

$$
\begin{aligned}
& E(k)=\int_{0}^{\pi / 2} \sqrt{1-k^{2} \cos ^{2} \psi} \mathrm{d} \psi \\
& D(k)=\frac{k^{2} E(k)}{\left(1+k^{2}\right) E(k)-\left(1-k^{2}\right) K(k)} \\
& K(k)=\int_{0}^{\pi / 2} \frac{1}{\sqrt{1-k^{2} \cos ^{2} \psi}} \mathrm{d} \psi
\end{aligned}
$$

where $k^{2}=1-(a / c)^{2} ; c$ denotes half the crack surface length.

For cracks with $a<<t$, the bending component can be ignored, resulting in a simpler expression for the opening compliance, $r$, of the crack:

$$
r=\frac{\delta}{\sigma_{T}}=\frac{S 4\left(1-v^{2}\right)}{E E(k)} a
$$

The function $E(k)$ does vary slightly with surface crack length; for $a=25 \mu \mathrm{m}$ and $c=15$ $\mu \mathrm{m}, E(k)=2.13$; for $a=25 \mu \mathrm{m}$ and $c=25 \mu \mathrm{m}, E(k)=1.57$, and is weakly dependent on $a$, increasing, for instance, by less than $6 \%$ as $a$ increases from $20 \mu \mathrm{m}$ to $30 \mu \mathrm{m}$ for a crack with $c=15 \mu \mathrm{m}$. For very shallow cracks (when a/t approaches 0 ), $S$ can be considered to be 1 . The compliances, $r$, for the two representative cases: $c=15 \mu \mathrm{m}$ and $c=25 \mu \mathrm{m}$, with $a=25 \mu \mathrm{m}$, are $0.22 \mathrm{~nm} / \mathrm{MPa}$ and $0.29 \mathrm{~nm} / \mathrm{MPa}$ respectively $(E=200 \mathrm{GPa}, v=0.3)$.

To check whether equation (5) approximates the wedge-shaped FIB notches satisfactorily, they were simulated using ABAQUS/Standard V6.10 with dimensions of $30 \mu \mathrm{m}(2 c) \times 25 \mu \mathrm{m}(a) \times 4 \mu \mathrm{m}$ (surface width) and $50 \mu \mathrm{m}(2 c) \times 25 \mu \mathrm{m}(a) \times 4$ $\mu \mathrm{m})$ within an 'infinite' plate $\left(10 \times 10 \times 10 \mathrm{~mm}^{3}\right)$. Using symmetry, one quarter of the geometry was modelled with tetrahedral elements, which are more convenient for the 
notch geometry; the difference between the crack mouth opening displacement of a semi-elliptical crack modelled by tetrahedral elements and the same geometry with 20 -node brick elements was calculated to be less than $0.2 \%$. The mesh independency of the simulation was verified. The compliances extracted from the simulations, were $0.31 \mathrm{~nm} / \mathrm{MPa}$ and $0.43 \mathrm{~nm} / \mathrm{MPa}$ for the 30 and $50 \mu \mathrm{m}$ long notches respectively. Compliance is thus affected by notch geometry, although the magnitudes are similar to equation (5).

Inspection of equation (5) shows that at $295 \mathrm{MPa}$, for notches and cracks of dimensions of interest to these experiments, the rate of change in maximum opening displacement, $\delta$, with crack growth is of the order of 2 to $5 \mathrm{~nm} / \mu \mathrm{m}$. The measured change in the maximum opening of notch 4 at $295 \mathrm{MPa}$ is $0.05 \mu \mathrm{m}$, implying crack extension of the order of 10 to $25 \mu \mathrm{m}$. The observed crack propagation of $16 \mu \mathrm{m}$ (Figure 9) is within this range. Changes in the opening displacement may thus be used to estimate the magnitude of fatigue crack propagation rates, without direct observation of the crack dimensions. The rate of change of crack opening was estimated by the secant method with adjacent measurement points, using the data in Figure 8; a nominal rate of change of opening displacement with crack extension of 3 $\mathrm{nm} / \mu \mathrm{m}$ was assumed. The maximum crack growth rates are thus estimated to be of the order of 1 to $2 \mathrm{~nm} /$ cycle (Figure 10). As discussed above, the systematic errors due to notch and crack geometry may be up to a factor of 2; nonetheless, this analysis shows that the order of magnitude of crack growth rates may be estimated by this method.

No attempt is made to relate these crack growth rates to environmental conditions, although it is noted that they are of the same magnitude as typical fatigue crack growth rates in austenitic stainless steel under BWR conditions, such as reported in [24]. There are variations in the growth rates that might be attributable to microstructure effects. For instance, in-situ 3D studies of fatigue crack nucleation from FIB notches have shown that several cracks may nucleate at the crack tip, subsequently coalescing as the crack extends [20]. Prior to coalescence, ligaments between these cracks would shield the crack tips from the applied load range; the apparent incubation observed in ambient temperature test may thus be due to the period prior to coalescence of cracks at the notch tip. The cyclic frequency was also reduced at 25,000 cycles, and this may also have encouraged crack propagation by corrosion fatigue. The different behaviours of HT-Crack 1 and 2 may be due to interactions with grain boundaries and their geometry; both cracks were nucleated intergranularly by stress corrosion, but might be expected to transition eventually to transgranular paths. Post-test characterisation of the notches and cracks would provide some insight into these processes, but it is the upper-bound values of crack growth rates that are most important and these may not have been reached in these preliminary experiments.

\section{Conclusions}

A new method for in-situ measurement of short crack propagation rates during a corrosion fatigue test of an austenitic stainless steel within a windowed autoclave has been demonstrated. Digital image correlation has been used to detect crack growth through measurement of the opening displacements of defects; either focused ion 
beam (FIB) milled notches from which fatigue cracks initiated, or stress corrosion cracks that subsequently propagated by fatigue. The measurement error in the change of crack opening displacement is less than $0.01 \mu \mathrm{m}$, allowing crack extension of a few $\mu \mathrm{m}$ to be detected. Multiple cracks can be developed in a single specimen, and observed simultaneously.

Although limited in scope, these experiments demonstrate that crack growth rate data for short corrosion fatigue cracks may be obtained using in-situ optical observation within a windowed "imaging autoclave", via digital image correlation analysis of notch opening behaviour. The measured crack propagation rates, at ambient and elevated temperature and pressure, are of the expected magnitude. Greater confidence in the crack growth rates could be obtained in a longer duration fatigue test, in which the cracks propagated further and where surface crack propagation rates could be measured, with crack detection enabled by digital image correlation.

Future work may use this methodology may study the effects of water chemistry; such as oxygen and hydrogen concentration, water temperature, cyclic waveform and stress state (uniaxial vs. biaxial). A similar autoclave may be developed to operate in aqueous environments at higher temperatures, such as those relevant to nuclear pressurised water reactor (PWR); the sapphire window seal and the chemical resistance of the sapphire to the test environment are the factors that limit the current system to $250^{\circ} \mathrm{C}, 50$ atmospheres.

\section{Acknowledgements}

The support of Rolls-Royce Ltd. in the development of the windowed imaging autoclave is gratefully acknowledged. We are grateful to M. Mostafavi (University of Oxford) for the elastic finite element solution.

\section{References}

1. O.K. Chopra, W.J. Shack, A review of the effects of coolant environments on the fatigue life of LWR structural materials, Journal of Pressure Vessel Technology 131 (2009) 0214091-02140921

2. H.P. Seifert, S. Ritter, H.J. Leber, Corrosion fatigue initiation and short crack growth behaviour of austenitic stainless steels under light water reactor conditions, Corrosion Science 59 (2012) 20-34

3. A. Turnbull, Modelling of crack chemistry in sensitized stainless steel in boiling water reactor environments, Corrosion Science 39 (1997) 789-805

4. A. Turnbull, 2009 W.R. Whitney award lecture: Local hydrogen generation and its impact on environment-assisted cracking and crevice corrosion. Corrosion 66 (2010) 0550011-05500111

5. N. Acuña, Fatigue corrosion cracking of an austenitic stainless steel using electrochemical noise technique, Anti-Corrosion Methods and Materials 52 (2005) 139-144

6. Y. Watanabe, F. Kimura, T. Shoji, Electrochemical noise in slow strain rate tests of a type 316 stainless steel in high-temperature high-pressure water, Zairyo to Kankyo/Corrosion Engineering 45 (1996) 667-673 
7. T.J. Marrow, H. Çetinel, M. Al-Zalmah, S. MacDonald, P.J. Withers and J. Walton, Fatigue Crack Nuclei in Austempered Ductile Cast Iron, Fatigue Fract. Engng Mater. Struct. 25 (2002) 635-648

8. R. Akid, K.J. Miller, Short fatigue crack growth behaviour of a low carbon steel under corrosion fatigue conditions, Fatigue and Fracture of Engineering Materials and Structures 14 (1991) 637-649

9. P. M. Wood, J. A. Duff and T. J. Marrow, Imaging Autoclave Development for In-Situ Optical Measurement of High Temperature Aqueous Corrosion Processes, 12th International Conference on Fracture, ICF12, 12-17 July, Ottawa, Canada, 2009.

10. J. Quinta da Fonseca, P. M. Mummery and P. J. Withers, Full-field strain mapping by optical correlation of micrographs acquired during deformation, Journal of Microscopy 218 (2005) 9-21

11. H. Li, J. Duff and T.J. Marrow, In-situ observation of crack nucleation in nuclear graphite by digital image correlation. Proceedings of PVP2008 ASME Pressure Vessels and Piping Division Conference, July 27-31, 2008, Chicago, Illinois, USA. Paper PVP2008-61136.

12. M. Mostafavi and T.J. Marrow, In situ observation of crack nuclei in polygranular graphite under ring-on-ring equi-biaxial and flexural loading, Engineering Fracture Mechanics 78 (2011) 1756-1770

13. M.A. Aswad and T.J. Marrow, Intergranular crack nucleation in polycrystalline alumina, $18^{\text {th }}$ European Conference on Fracture, ECF18, Dresden (Germany), 30 Aug-3 Sept 2010.

14. A. Cook, J. Duff, N. Stevens, S. Lyon, A. Sherry and T.J. Marrow, Preliminary Evaluation of Digital Image Correlation for In-situ Observation of Low Temperature Atmospheric-Induced Chloride Stress Corrosion Cracking in Austenitic Stainless Steels, 216th ECS Meeting, Vienna, Austria, 2009

15. S. Rahimi, D. L. Engelberg, J. A. Duff and T. J. Marrow, In-situ Observation of Intergranular Crack Nucleation in a Grain Boundary Controlled Austenitic Stainless Steel, Journal of Microscopy 233 (2009) 423-431

16. J. Kovac, C. Alaux, T.J. Marrow, E. Govekar, A Legat, Correlations of electrochemical noise, acoustic emission and complementary monitoring techniques during intergranular stress-corrosion cracking of austenitic stainless steel, Corrosion Science 52 (2010) 2015-2025.

17. S. Rahimi and T. J. Marrow, Effects of orientation, stress and exposure time on short intergranular stress corrosion crack behaviour in sensitised type 304 austenitic stainless steel, Fatigue and Fracture of Engineering Materials and Structures 35 (2012) 359-373

18. M. Kuroda and T.J. Marrow, Modeling the effects of surface finish on fatigue limit in austenitic stainless steels, Fatigue and Fracture of Engineering Materials and Structures 31 (2008) 581-598.

19. S. Al-Shahrani, and T.J. Marrow, Effect of Surface Finish on Fatigue of Stainless Steels, 12th International Conference on Fracture, ICF12, 12-17 July, Ottawa, Canada, 2009

20. A. King, W. Ludwig, M. Herbig, J-Y. Buffiere. A.A. Khan, N. Stevens and T.J. Marrow, Three-dimensional in situ observations of short fatigue crack growth in magnesium, Acta Materialia 59 (2011) 6761-6771

21. LaVision, DaVis StrainMaster Software Manual 7.1.2006, LaVision GmbH, Gottingen. 
22. D.Z. Feng and Q.C. Hong, Investigation of surface crack opening displacement and its application in pressure vessels and piping. International Journal of Pressure Vessels and Piping 52 (1992) 227-239

23. J.C. Newman and I.S. Raju, An Empirical Stress Intensity Factor Equation for the Surface Crack, Engineering Fracture Mechanics 15 (1981) 185-192.

24. M. Urquidi-Macdonald, Kohonen mapping of the crack growth under fatigue loading conditions of stainless steels in BWR environments and of nickel alloys in PWR environment, Journal of Nuclear Materials 379 (2008) 68-79

\section{Figure Captions}

Figure 1: Windowed Imaging Autoclave; a) autoclave chamber and loading jig; push rod slide bearing (1); push rod (2); main autoclave seal (3); sapphire window (4) b) Optical system, comprising XY-Z precision stage, optical extension tube and switching mirror for optical or Raman observation.

Figure 2: Scanning electron microscope (SEM) image of FIB Notches 1 to 4, prior to the ambient temperature fatigue test.

Figure 3: An example of a stress corrosion crack selected for corrosion fatigue propagation testing (HT-crack 1). Imaged by conventional optical microscopy (a) before the start and (b) after the end of the corrosion fatigue test. The dotted arrows mark the approximate length of the crack nuclei. The crack nucleus was identified before the corrosion fatigue test by digital image correlation analysis (c) of images recorded at the end of a static stress corrosion test, with and without load; the strain map shows the component of strain parallel to the loading direction (left to right; the maximum strain is 0.046 , strains below 0.015 are not shown).

Figure 4: Optical images of the ambient temperature sample, viewed through the sapphire window with water inside the Imaging Autoclave; a) raw image, b) montage stitched image obtained from a $3 \times 3$ grid of observations after processing to enhance contrast. The total observed area is approximately $0.75 \mathrm{~mm} \times 0.75 \mathrm{~mm}$.

Figure 5: SEM images of the FIB notches after fatigue testing in ambient temperature water for $\sim 33,500$ cycles.

Figure 6: Displacement map (in units of pixels) obtained by correlation of images from the ambient temperature fatigue test; a) at 0 cycles between minimum and maximum stress; b) at 33,500 cycles between minimum and maximum stress; c) between 0 cycles and 33500 cycles at peak stress; and d) between 0 cycles and 33500 cycles at minimum stress. The relative displacements are calculated in the direction of the applied stress (perpendicular to the notch). The locations of the notches have been masked (Notch 1 to Notch 4 from left to right). The displacement scales in (a) and (b) are the same, as are those in (c) and (d). The maximum stress is $295 \mathrm{MPa}$ and the minimum stress is $7 \mathrm{MPa}$.

Figure 7: Images within the autoclave at maximum load of HT-crack 1, with superposed maps of the maximum normal strain obtained by DIC with respect to the initial image at load. Strains below a threshold of 0.02 are not shown. The DIC analysis window was $128 \times 128$ pixels, with $87 \%$ overlap. 
Figure 8: Change in notch and crack opening displacement with number of fatigue cycles for FIB notches (ambient temperature) and SCC-induced cracks (elevated temperature)

Figure 9: FIB sectioning at the centre of Notch 4; a crack is observed ahead of the FIB notch after straining in tension. The sample is tilted at $45^{\circ}$ (axis perpendicular to the notch) and the image is not tilt-corrected. Some re-deposition of the Platinum infilling of the notch has occurred, spreading its profile.

Figure 10: Estimated crack growth rates, based on the sensitivity of crack opening to crack extension. The uncertainties are from the measurement error standard deviation; systematic errors to due crack or notch geometry are up to a factor of approximately 2 . 
Figure 1
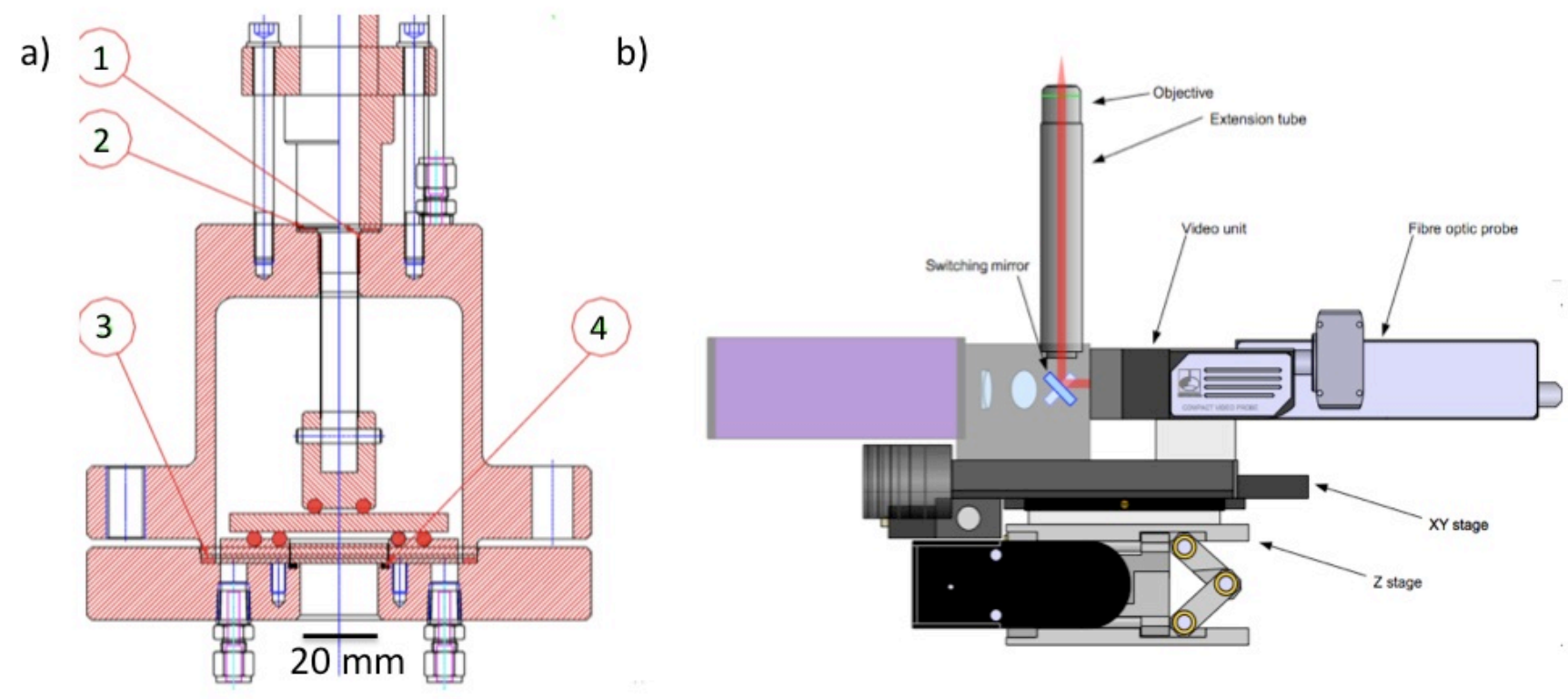
Figure 2

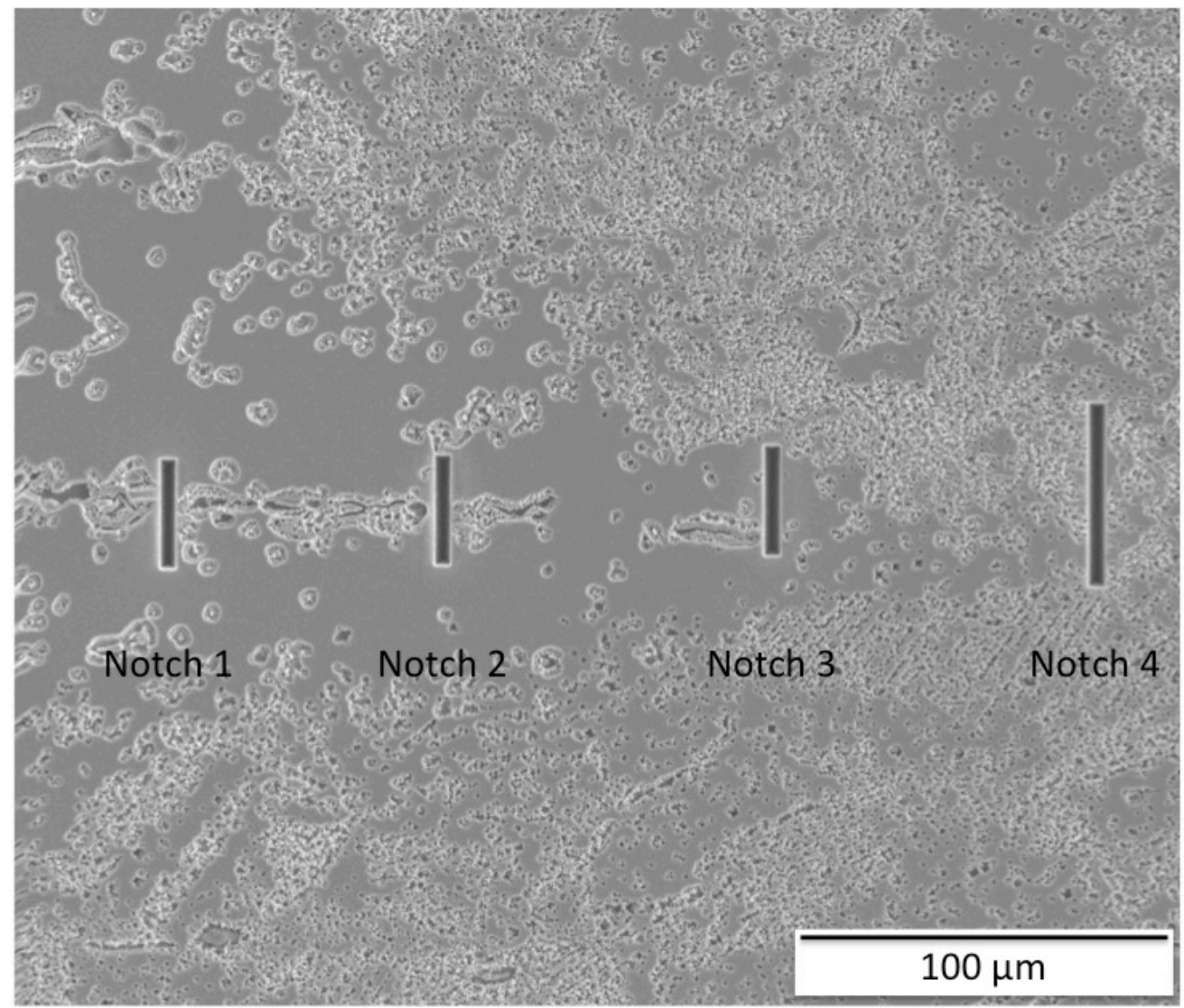


Figure 3

a)

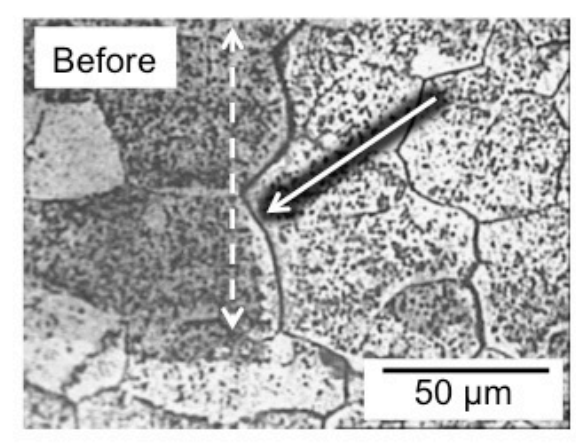

b)

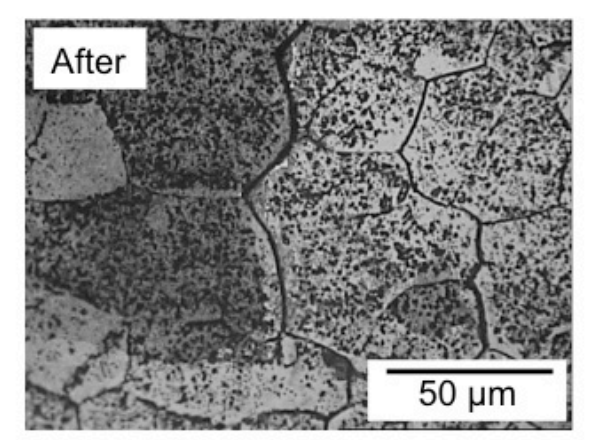

c)

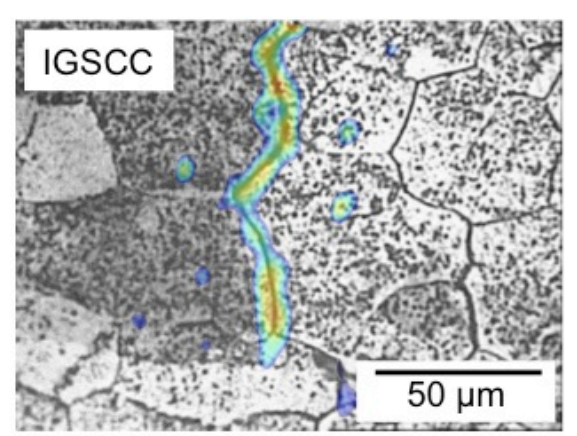


Figure 4
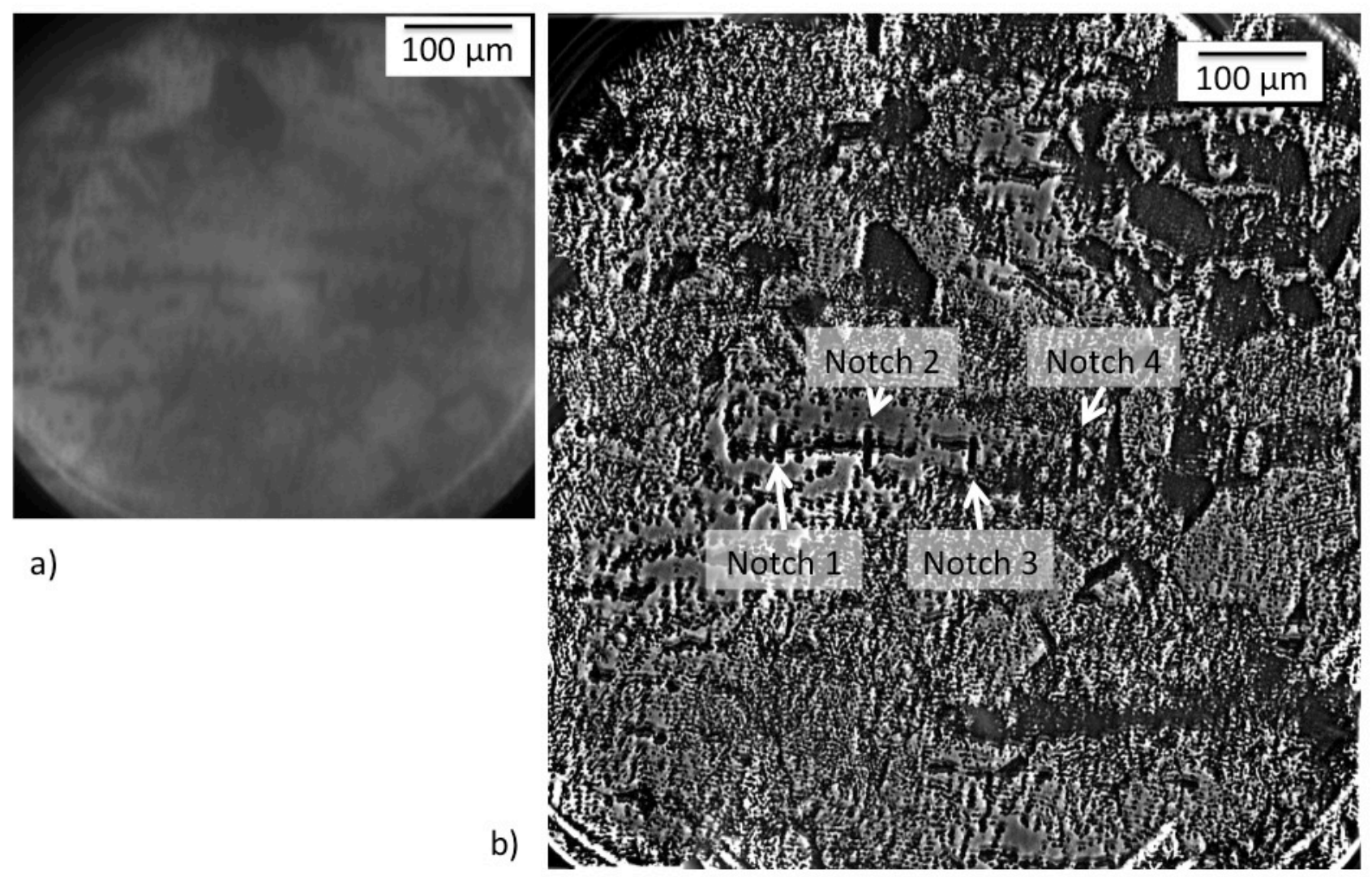

a)

b) 
Figure 5
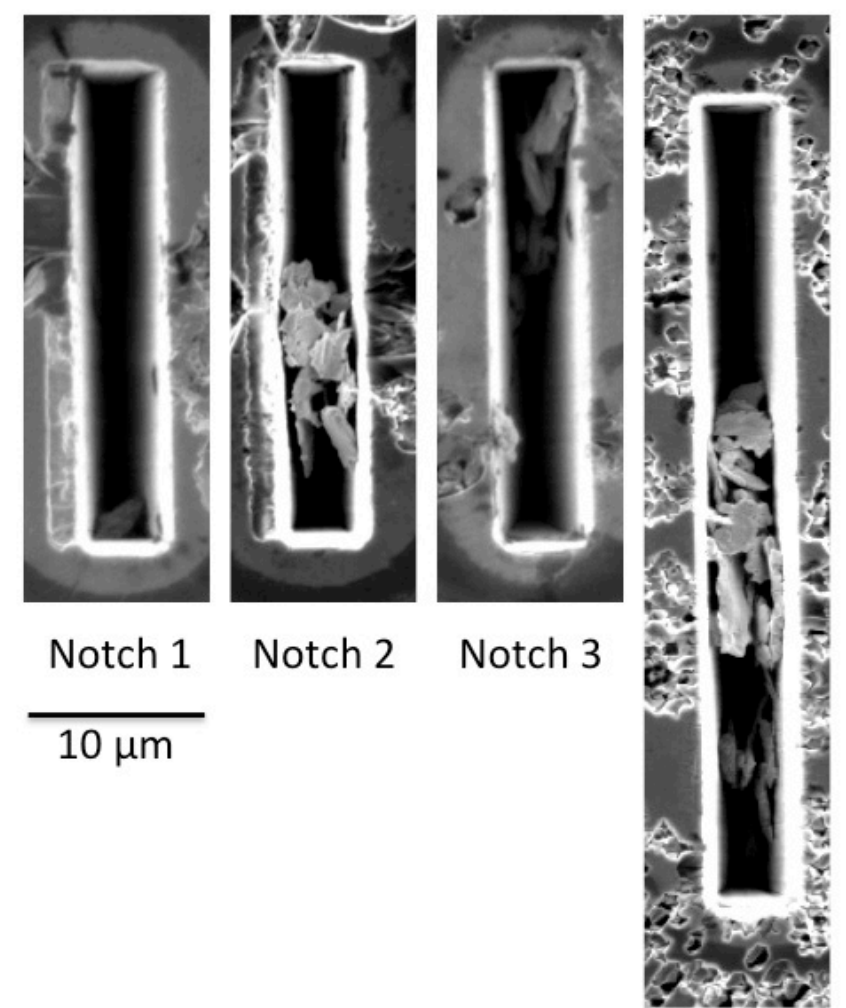

Notch 4

Notch 1 Notch 2 Notch 3

$10 \mu \mathrm{m}$ 
Figure 6
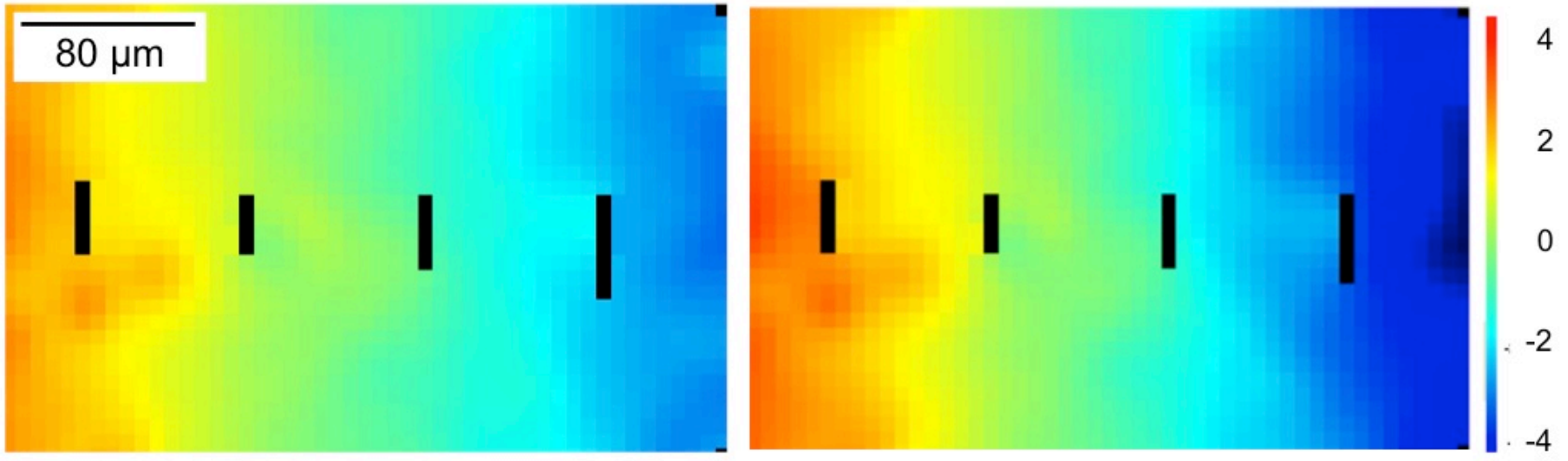

a)

b)
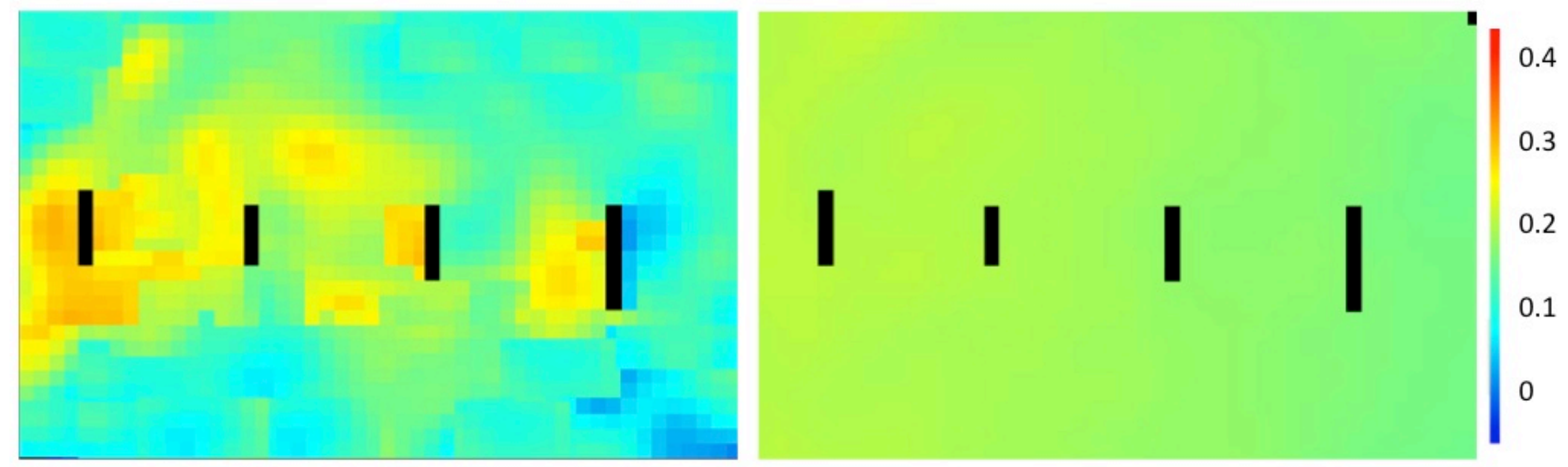

c)

d) 
Figure 7
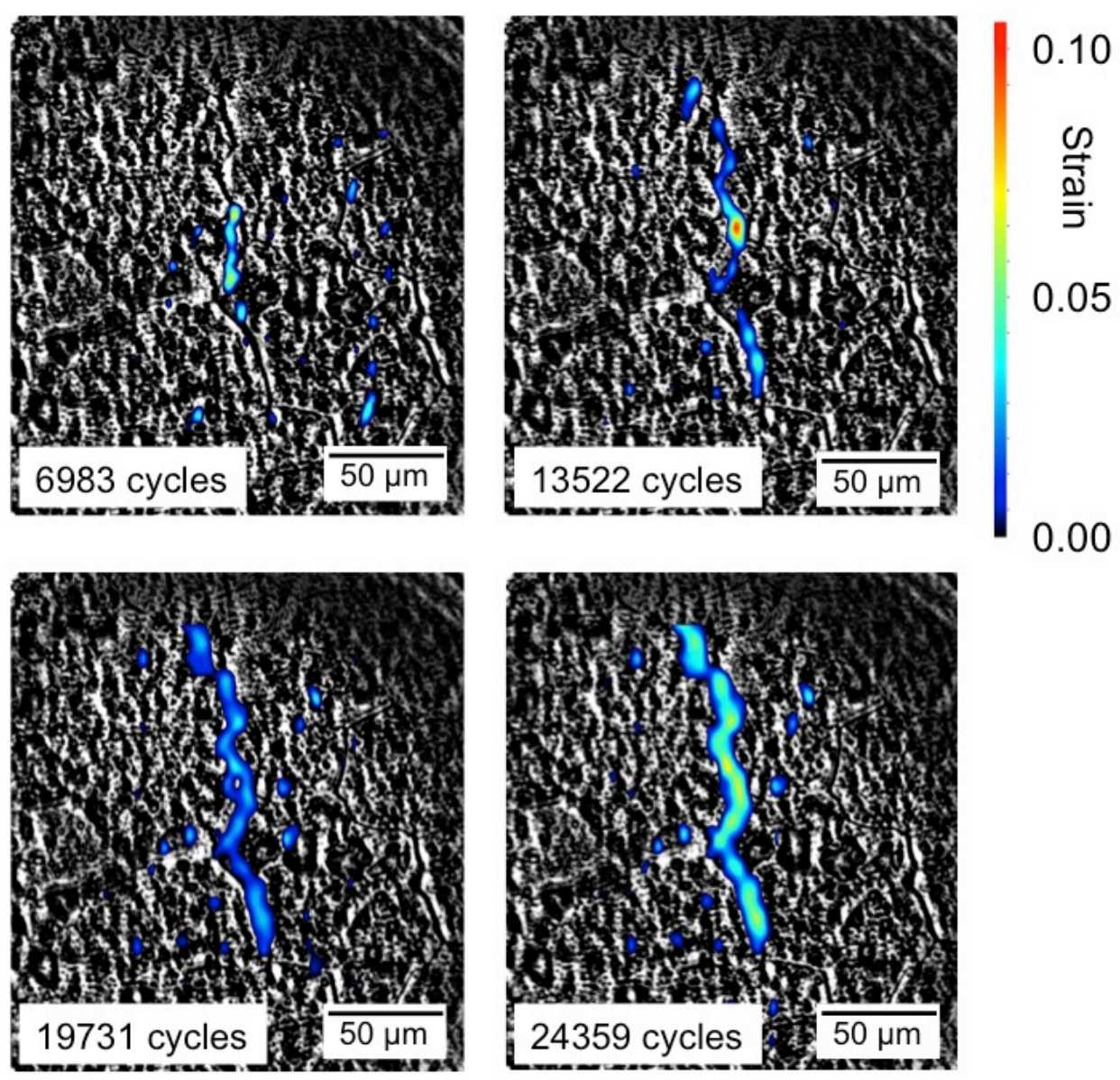
Figure 8

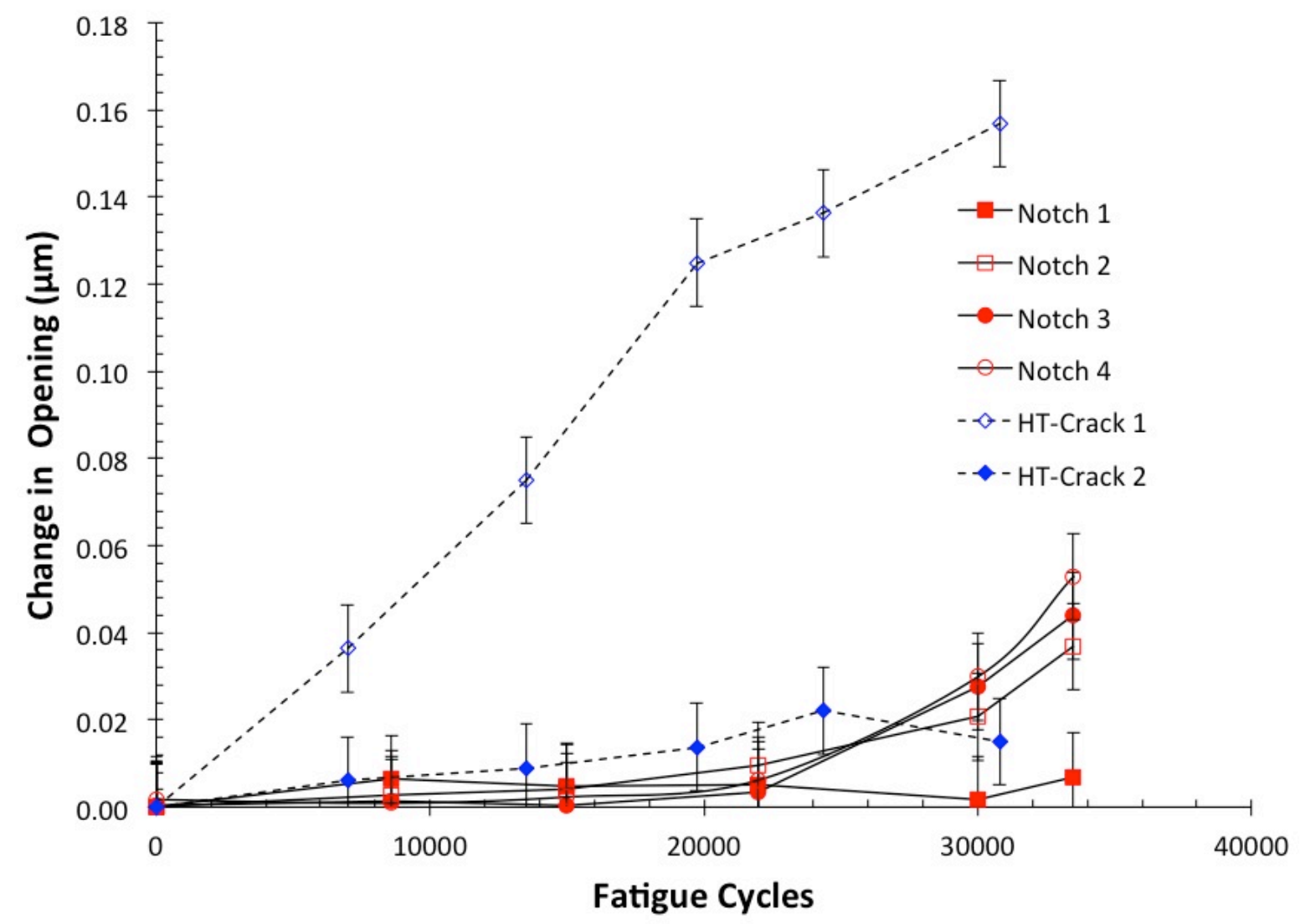


Figure 9

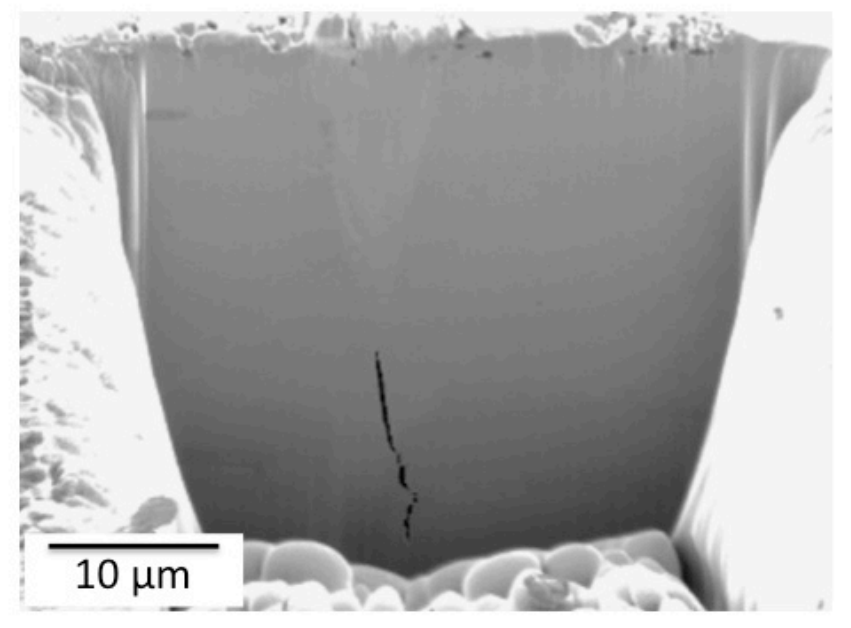


Figure 10

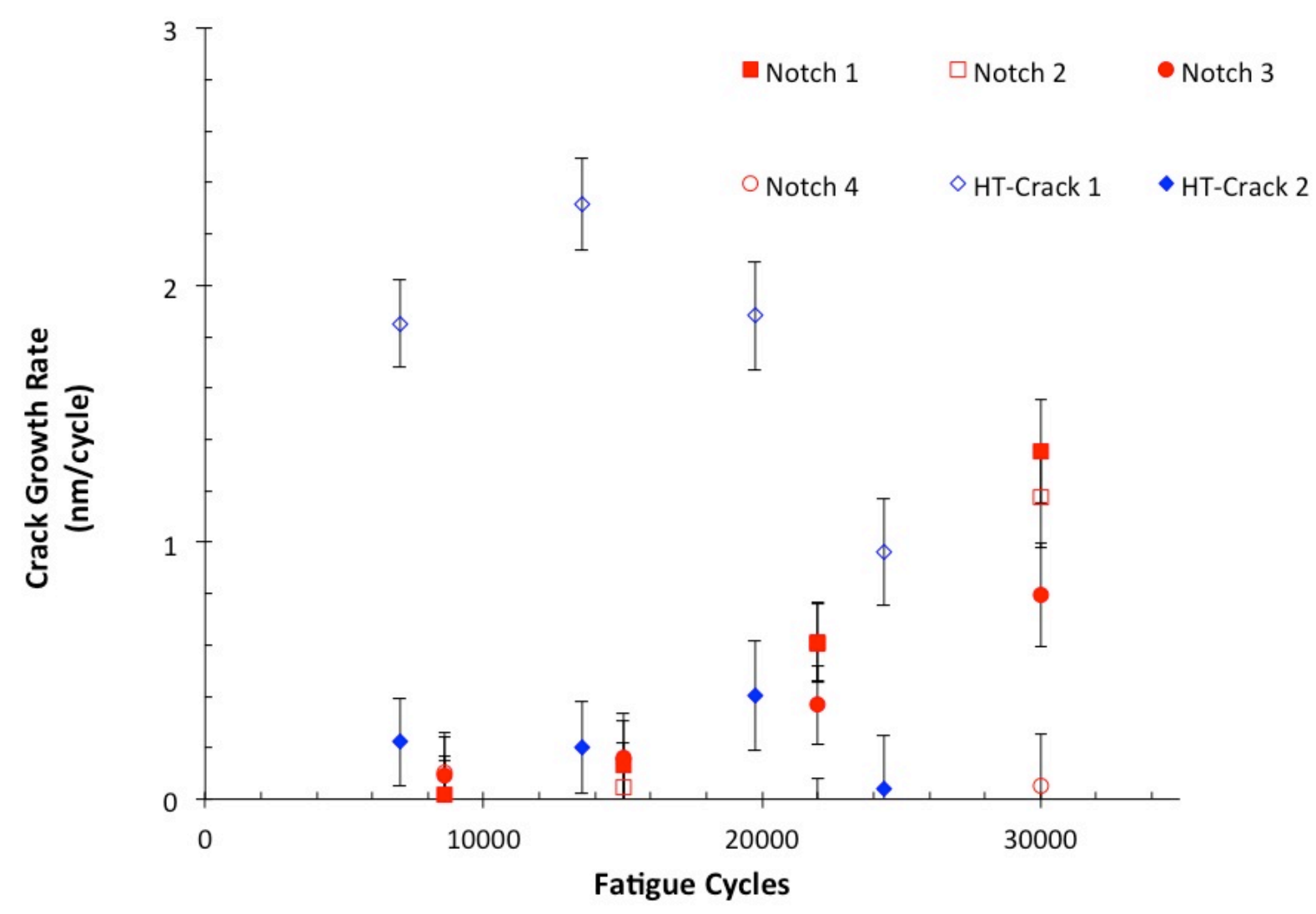

